Britain, with a full-time chairman and secretary, should be constituted by the Central Government in India to advise on the distribution of funds available. Such a body would be in a position to give authoritative advice and guidance to the universities, without interfering with their economy, not only in regard to general expansion, but also as to the special lines of research they can most usefully undertake. There is a similar need for collaboration between the universities and various research institutions in the country, and particulars of some of the institutes which function as common federal institutions for advanced technical training and research are included in the paper. Some reference to the corporate life in the universities and the importance of continued contact between British and Indian universities both in regard to teaching, research and students is also included.

\section{Tercentenary of the Calculating Machine}

The first calculating machine was invented in 1642 by Blaise Pascal. Had it not been for the War, the tercentenary of this event, which has had such a profound influence on applied mathematics and physics, would have been appropriately celebrated in Paris. In order that the date may not pass unnoticed, a small committee representing the Fighting French and British men of science, inventors and users has arranged a memorial luncheon to be held on October 19, at the Connaught Rooms, Great Queen Street, London, W.C.2, at 12.30 for 12.45 p.m. Prof. S. Chapman, president of the Royal Astronomical Society, will propose the toast of "Pascal-the inventor of the first calculating machine". The reply will be by Prof. R. Cassin, Commissaire National à la Justice et l'Instruction Publique. Other members of the Fighting French and French men of science in Great Britain will be present. Invitations are being sent to those who have been conspicuously associated with the development of calculating mechanisms, and to distinguished users of calculating machines, both scientific and industrial ; tickets can be obtained from Miss M. E. Purves, 23 Bedford Square, London, W.C.I.

The luncheon will be followed by a small exhibition from 3 until 6 p.m. of calculating machines, with particular emphasis on models to show the actual mechanical working. A replica of the first machine made by Pascal will be exhibited and also a replica of the first calculating machine made in England by Samuel Morland in 1666. Demonstrators, in no way connected with the selling of machines, will explain the machines and models to visitors. Two 15-minute lectures have also been arranged, one at 3.30 by Dr. L. J. Comrie on "Mathematical Gymnastics with Calculating Machines", and the other at 4.30 by $\mathrm{Mr}$. R. S. Nilsson on "A Description of Calculating Machine Mechanisms"

\section{The British Astronomical Association}

ON the invitation of the president and council of the Royal Astronomical Society, the British Astronomical Association is to be accommodated in future in the rooms of the former at Burlington House, London. Negotiations have been proceeding for some months and the final arrangements were completed in time for the British Astronomical Association to hold its first meeting in the new premises on September 30. A large part of the proceedings was devoted to a survey of the history of the Association since it was founded in 1890 , special mention being made of its founder, Mr. Edward Walter Maunder. A number of members spoke about the progress of the Association during the fifty-two years of its existence and about the influence of many of its past members in shaping its policy and assisting with its remarkable development. It is worth noticing that the present international crisis has not affected its membership adversely-an indication of the interest which the amateur possesses in various astronomical branches. The new premises provide more adequate accommodation for the library and in other ways supply great facilities for the members, to whom the change has given considerable satisfaction.

\section{Conference of Scientific Workers at Manchester}

ON September 27, the North-West Area Committee of the Association of Scientific Workers arranged an all-day conference in Manchester on "Science and Total War". Opening the morning session, Prof. H. Levy asked the conference to consider the scientific effort of the country against the background of the slavery to which, literally, Hitler is subjecting the scientific workers and peoples of Europe. Total war demands total production at home, total production in the scientific sense. One of the biggest factors in ensuring total production, he said, are the production committees at which management and workers may overcome their traditional antagonism. Research must be centrally and co-operatively organized. The armed forces should select their officers scientifically and should ensure that there are sufficient technicians in the field to deal with problems as they arise.

Mrs. Barbara Ruheman described the contribution of science to the war-effort of the U.S.S.R., stressing the central position held by the Soviet Academy of Sciences in all Russian planning schemes. There is an intimate collaboration between the designer of a new fighter, for example, and the pilots who actually fly it. At the afternoon session difficulties arising in the working of production committees were discussed by speakers representing shop-stewards, engineers and chemists. These contacts were valuable in breaking down misunderstandings between workers and technicians. Resolutions were passed supporting the establishment of a whole-time central scientific and technical planning board, urging the strengthening of the Ministry of Supply's Synthetic Rubber Committee by the inclusion of technical experts, and the pooling of information, especially between firms engaged on medicinal research and production.

\section{Biology and Control of the Bed-bug}

The Medical Research Council has recently issued in its Special Report series, No. 245, a "Report of the Committee on Bed-bug Infestation 1935-1940" (H.M. Stationery Office, 1942. Is. net). It is in the form of a 64-page brochure which comprises six sections on the subject, concerned with the varied aspects of the problem, each being contributed by different specialists. In the section on new data bearing upon the ecology of the bed-bug, it is gathered that, provided a source of blood is available, temperature is the most important environmental factor. In unheated rooms the winter mortality of the bug population may be as high as 80 per cent, whereas in warmed rooms the population tends to increase enormously 